
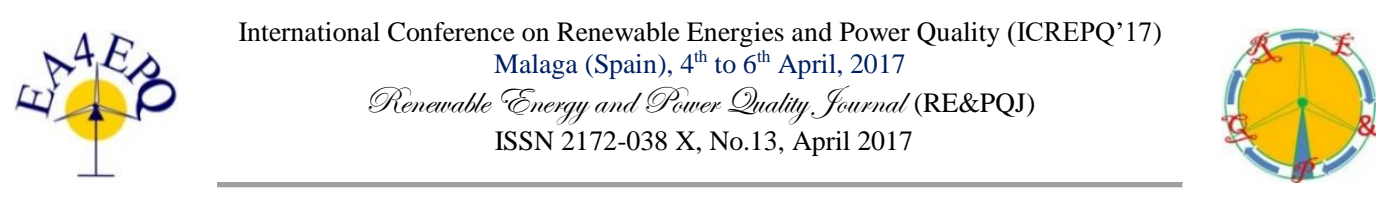

\title{
Testing and analysis of a fuel cell based stand-alone power system for residential use
}

\author{
J. García-Villalobos ${ }^{1}$, I. Zamora ${ }^{1}$, J. I. San Martín ${ }^{2}$, F. J. Asensio², I. Junquera ${ }^{1}$ \\ Department of Electrical Engineering \\ University of the Basque Country (UPV/EHU) \\ ${ }^{1}$ Alameda Urquijo, s/n, 48013 Bilbao (Spain) \\ ${ }^{2}$ Avenida Otaola, 29, 20600 Eibar (Spain) \\ e-mail: javier.garciav@ehu.eus
}

\begin{abstract}
Nowadays, there are residential buildings which cannot be connected to a distribution network, due to the lack of electric infrastructure. Also, there are other electric applications where it is necessary to have a back-up system, i.e. hospitals, hotels, etc. Additionally, there are users who just want to be off-grid. In all these cases, a dedicated stand-alone generation system can provide a valuable service.

In this context, this paper is focused on testing and analysis of a real small stand-alone generation system composed by two proton membrane exchange fuel cells (PEMFC) and a micro wind generator (WG). The key feature of this configuration is to be an on-site zero-emission system. Additionally, quality of supply and energy efficiency of this microgrid in islanded mode are analyzed. Furthermore, possible optimization methods and future enlargements of the system are proposed, in order to improve the overall efficiency of the proposed microgrid.
\end{abstract}

\section{Keywords}

Fuel cell, wind turbine, zero emissions, stand-alone, offgrid, microgrid

\section{Introduction}

Currently, most customers are connected to a large electric grid in order to get cheap and reliable electric supply. The electric grid provides several services that should not be despised. However, the geographic coverage of these electric grids is limited due to economic or environmental reasons. It is estimated that 1200 million people live without access to electricity [1].

Furthermore, there is a potential market of customers who want to go off-grid, i.e. being energetically self-sufficient, even though, it is not economically profitable most of the times. Another crucial characteristic of this type of customers is being environmentally sensitive. In other words, they do not want to emit any type of pollutants with their electric installation. In all these applications, a zeroemissions off-grid power system may cover these needs.
There are several types of stand-alone power systems depending on the generation system and the energy storage technology used [2]. Currently, the most popular one is the combination of photovoltaic solar panels and electric batteries. However, the use of batteries can be expensive, especially in systems with high reliability requirements. Additionally, even modern lithium-ion batteries have a limited lifetime which depends on several factors such as battery chemistry, battery cycling, operation temperature, etc. As an example, lithium-ion batteries can last up to 10 years or about three to seven thousand equivalent full cycles, before reaching their end-of-life.

As an alternative, compressed hydrogen storage and proton membrane exchange (PEM) fuel cells can be used [3]. This technology has several advantages, such as low temperature operation, low maintenance and modular design. Additionally, the energy density of compressed hydrogen is noticeably higher than any other commercial electrochemical battery technology and compressed hydrogen storages can be re-filled in few minutes if needed [4]. On the other hand, fuel cells also produce heat that can be used for heating purposes, improving the overall efficiency of the system.

Regardless the technology used in those microgrids, the most important characteristic is the ability of working in islanded mode, to improve the reliability of the system. The quality of supply of such systems should be better or at least similar to the one offered by the utility grid. Bollen et al. [5] give several recommendations and propose voltage and frequency performance factors for microgrids based on the EN50160 standard [6].

Taking into account these aspects, this paper presents an analysis, with regard to efficiency and quality of supply, of a real microgrid composed by two PEMFCs and a small wind generator. The total power of the system is $3.2 \mathrm{~kW}$, which should be enough for powering a small house or other small applications.

Several tests have been performed on this microgrid, which include load demand variation, motor start-ups, wind generation changes and generation loss. All the 
recorded measurements have been obtained using a power quality analyzer, which follows the EN50160 standard.

This paper is organized as follows. Section 2 presents the overall system characteristics and the elements of the analyzed microgrid. Section 3 shows some of the tests carried out and the obtained results in each one. On the other hand, Section 4 proposes some design optimization alternatives to improve overall efficiency of the system. Finally, Section 5 summarizes the main conclusions of the paper

\section{Microgrid system description}

In this section, the real microgrid tested in this paper is introduced, as well as a brief description of each element.

\subsection{Overall system overview}

The microgrid is composed by two PEMFC systems, one double-fed wind generator and three single-phase inverters. Both fuel cells are fed through individual compressed storages of hydrogen. These fuel cells are connected in parallel to a DC bus, after their respective DC/DC converters. This DC bus feeds the three single-phase DC/AC converters, of $1 \mathrm{kVA}$ each, which are synchronized to generate a three-phase network, needed to coupling the double-fed asynchronous wind generator to the microgrid. Figure 1 shows the stand-alone power system layout while Figure 2 displays the implementation of the analyzed microgrid, in the laboratory.

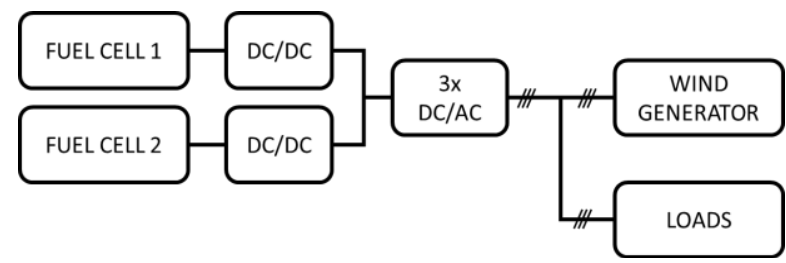

Figure 1. Overall system overview layout

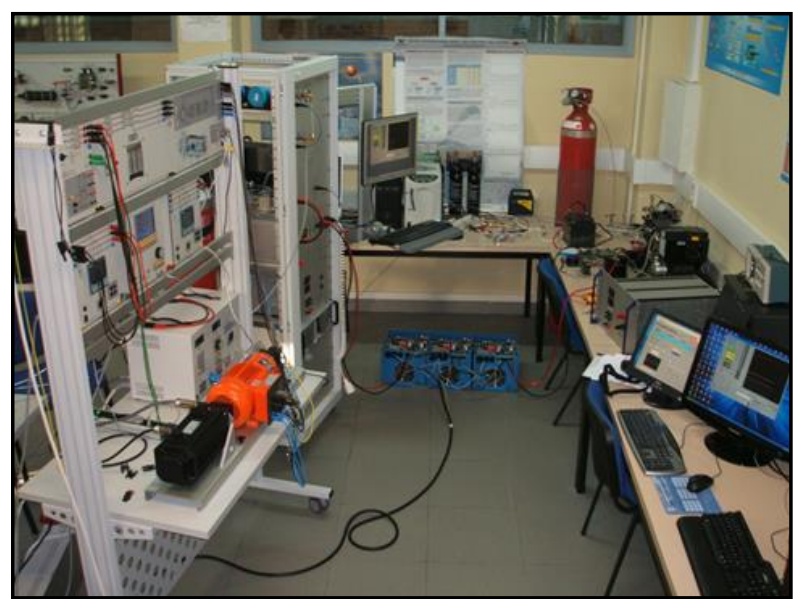

Figure 2. Microgrid tested in the laboratory

\subsection{PEM fuel cells}

Two Nexa Ballard PEM fuel cells have been used in these tests, having the same characteristics and rated power $(1.2 \mathrm{~kW}$ each). As all fuel cells, they produce unregulated DC power and therefore, a DC/DC converter is necessary to obtain near constant output DC voltage, in this case $26 \mathrm{~V}$. Additionally, each fuel cell has two small auxiliary batteries of $12 \mathrm{~V}$ and $18 \mathrm{Ah}$. These batteries are connected in series and they are used for start-up purposes, feed auxiliary devices of the fuel cell module and increase the response time of the system with fast load demand changes. The fuel cell systems are responsible of balancing the whole system, to maintain a constant frequency of $50 \mathrm{~Hz}$.

Regarding the efficiency of the PEMFC systems, it is variable in function of several parameters such as load demand, operation temperature, etc. The maximum electrical efficiency of the fuel cell systems is $52 \%$ at $0.33 \mathrm{~kW}$ of load demand and an operation temperature of $65^{\circ} \mathrm{C}$. However, the efficiency of the PEMFCs can be improved if the thermal energy produced by the fuel cells is used. In this case, the efficiency of a PEMFC can achieve a value near $80 \%$.

\subsection{Single-phase inverters}

Three single-phase inverters are used to convert the DC power generated by the fuel cells into a three-phase AC power. The output voltage of the inverters is the standard $400 \mathrm{~V}$ phase to phase and the total rated power is $3 \mathrm{kVA}$. Thus, the maximum allowed energy demand per phase is limited to $1 \mathrm{kVA}$.

\subsection{Double-fed wind generator}

The wind generator is based on a double-fed asynchronous electric machine, with a rated power of $0.8 \mathrm{~kW}$. The wind turbine performance is simulated using a servomotor, to apply different wind profiles to the generation system in the laboratory. Additionally, an isolating transformer and a synchronization device are used to connect the wind generator to the three-phase network of the microgrid.

\subsection{Electric loads}

Several types of loads, conditions and events have been tested to analyze the performance of the system. Among the loads tested, there are twelve discharge lamps of $0.15 \mathrm{~kW}$ for lightning purposes and a three-phase asynchronous motor of $0.6 \mathrm{~kW}$, which can be used as a water pump in isolated areas.

A special mention should be dedicated to the discharge lamps. They produce high current peaks, with a value of up to 10 times their rated power, when they are connected to the network. Therefore, they induce current and voltage harmonics to the system.

\section{Microgrid tests and results}

The tests carried out include load demand variations, wind generation changes, starting of electric motors and hydrogen supply failures. These tests and their results, in terms of efficiency and quality of supply, are presented below.

\subsection{Test I. Load demand variation}

In this test, a load demand variation using the discharge lamps has been carried out. The energy demand of these lamps reaches a maximum value of $1.9 \mathrm{~kW}$. In this case, no wind generation has been considered. Figure 3 shows the active power generated by each PEMFC and the load demand. As can be seen, the PEM fuel cell number one (FC1) is in charge of supply the demanded power by the loads, when this demand is less than $1 \mathrm{~kW}$. This behavior is repeated in all scenarios. Thus, it can be concluded that 
FC1 has a more sensitive control of voltage and frequency than the second fuel cell (FC2).

Additionally, it should be pointed out that the sum of FC1 and FC2 output power is greater than the total load demand. This is due to the fact that the fuel cell output power refers to the gross fuel cell power, which also includes the power supply to auxiliary devices of the PEMFC system.

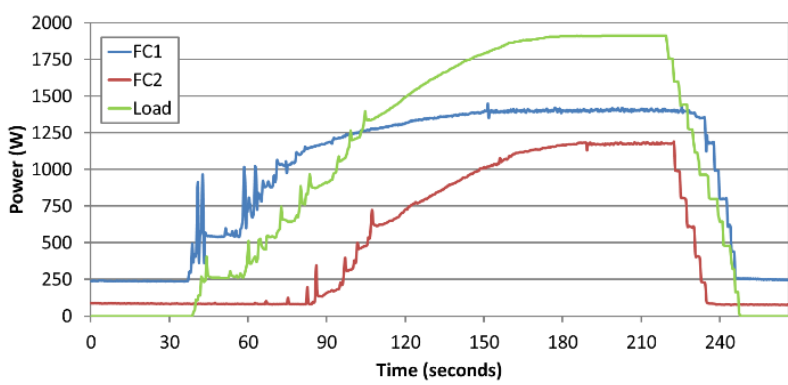

Figure 3. Active power supplied by fuel cells and load demand, during test I

The efficiency of each fuel cell, the total efficiency and the load demand are shown in Figure 4. The registered efficiency of FC2 at the beginning and end of the test must be not considered as it is in idle state. The electrical efficiency of the fuel cells ranges between 55 to $30 \%$, being fairly similar for both fuel cells when they provide similar output power. On the other hand, the overall electric efficiency goes from a minimum of $35 \%$ and a maximum of $50 \%$.

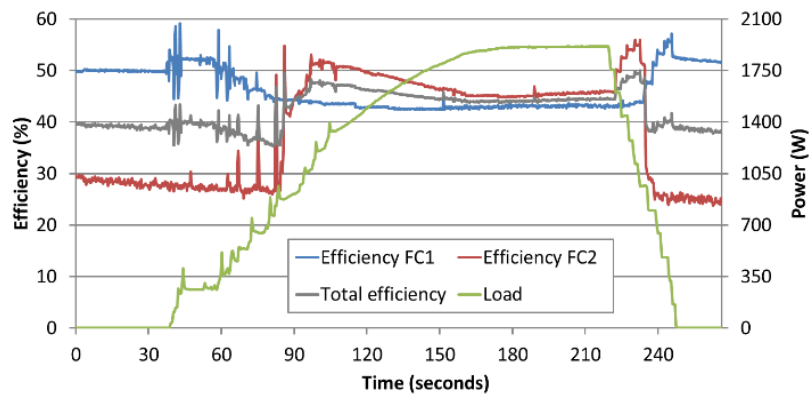

Figure 4. Fuel cells electrical efficiency and load demand, during test I

The inverters of the microgrid keep the rated voltage of the system near to $229 \mathrm{~V}$ in normal operation, as shown in Figure 5. However, the connection of the discharge lamps produces several voltage drops. The minimum recorded value of voltage is $220 \mathrm{~V}$. According to the EN50160 standard, supply voltage variations must be in the range of $\pm 10 \%$ of the declared voltage $(229 \mathrm{~V})$ for $95 \%$ of a week. Therefore, the voltage drops do not surpass the limit stablished in the EN50160 standard.

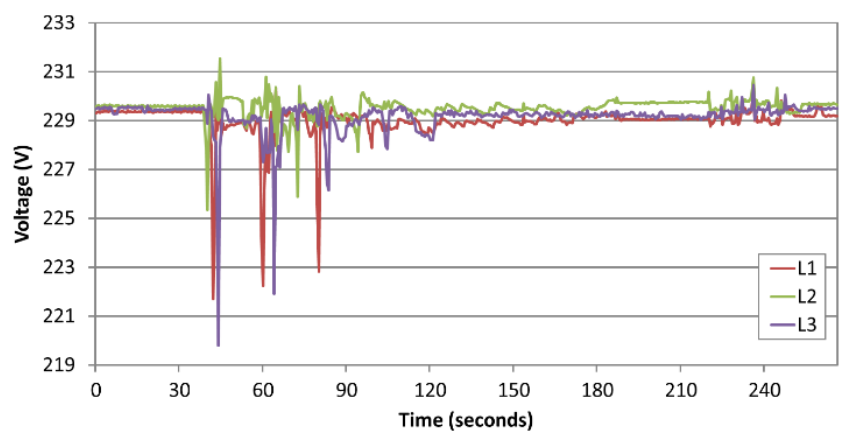

Figure 5. Line-neutral voltage for each phase, during test I
These discharge lamps also affect to the voltage harmonic levels and the total harmonic distortion (THD) of the microgrid. Figure 6 shows the maximum, average and minimum recorded values of voltage harmonics during the test. It is noteworthy the difference between the maximum and the average values of each harmonic, which is caused by the connection of the discharge lamps. On average, all the voltage harmonics are under the limits defined by the EN50160 standard, taking into account that these limits are stablished for $95 \%$ of the time in one week.

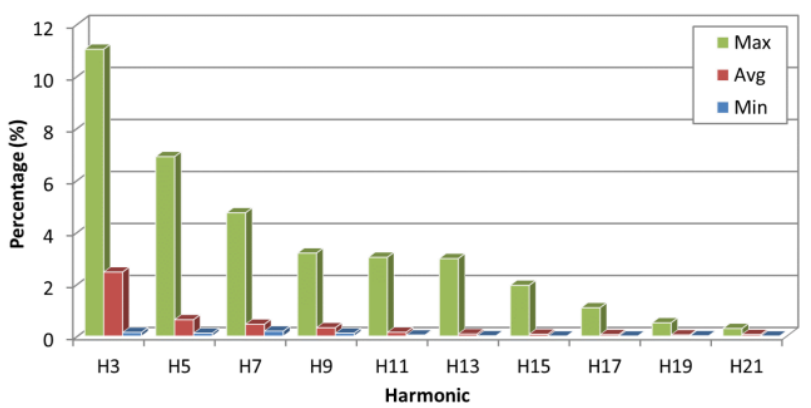

Figure 6. Voltage harmonic levels of phase one, during test I

Regarding to the THD value (Figure 7), it ranges between 1 and $4 \%$ with some peaks up to $16 \%$. A limit for THD value is stablished in the EN50160 and the EN61000-2-2 standard for public LV networks [7]. These standards specify a total voltage THD value of less than $8 \%$ for $95 \%$ of the time in one week. As THD values greater than $8 \%$ last less than three seconds of the total test time, the THD value remains within the standards limits.

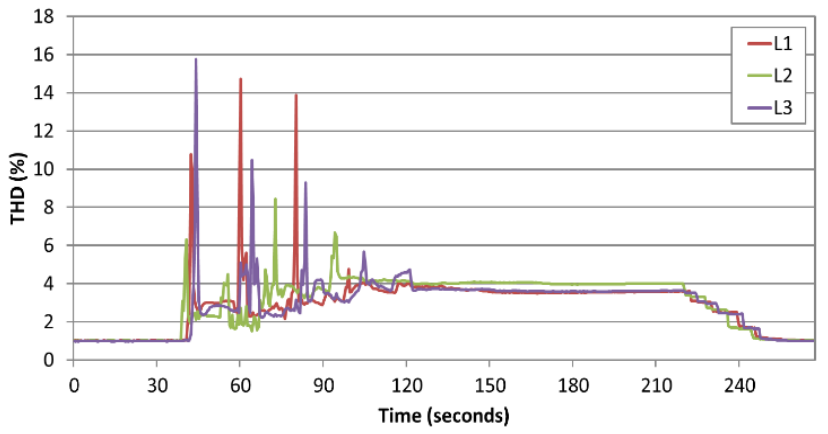

Figure 7. Voltage THD evolution for each phase, during test I

To finish this test, the frequency is presented in Figure 8. The frequency remains almost constant with very slight deviations during the test. In this sense, the microgrid keeps the frequency at $50 \mathrm{~Hz}$, without any noticeably deviation in all the performed tests.

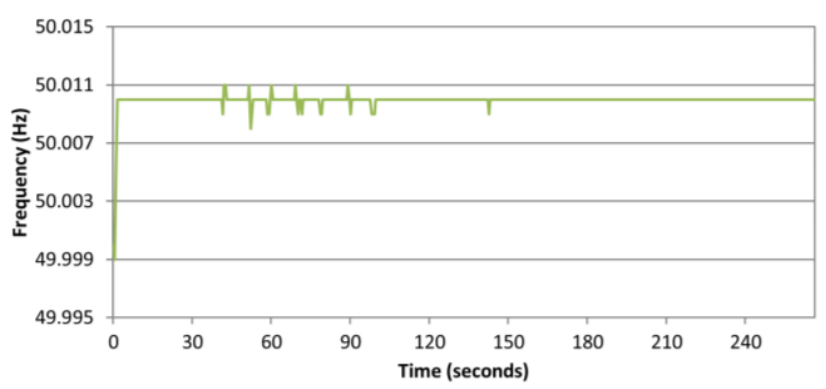

Figure 8. Frequency evolution, during test I

\subsection{Test II. Wind generation changes}

In this test, the energy produced by the wind generator is modified to analyze the behavior of the PEMFCs and the 
effect on the microgrid quality of supply, whereas the load demand is kept constant.

First of all, several parameters of the wind generator are shown in Figure 9. The wind generator is connected to the microgrid ten seconds, after the beginning of the test. As a consequence of this connection, the wind generator rotor speed is reduced, until an increase of wind speed is produced. The emulated wind speed profile reaches the maximum at the half of the emulation process. At that moment, the maximum rotor speed (1900 rpm) is reached.

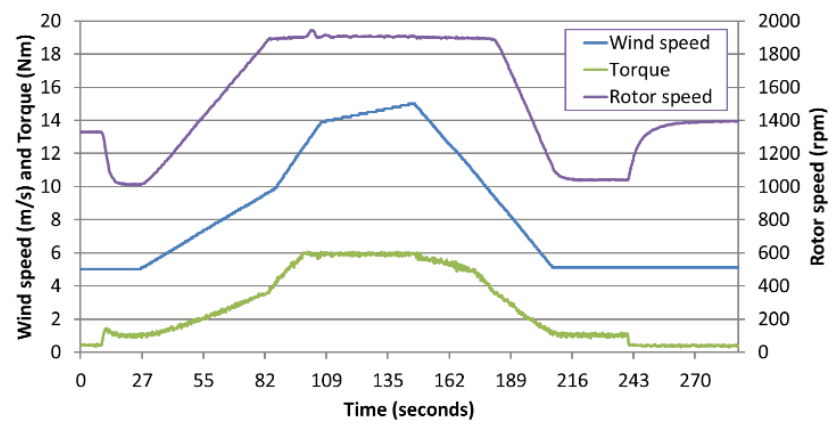

Figure 9. Parameters of the wind generator, during test II

As a consequence of the wind generation increase, the FC2 reduces its power supply automatically (Figure 10) due to the lower sensitivity of FC2 system to voltage deviations at the DC bus. An aspect that should be pointed out is that the wind generator (WG) behaves like a small load when it is connected to the microgrid, but there is no enough wind to start generating power.

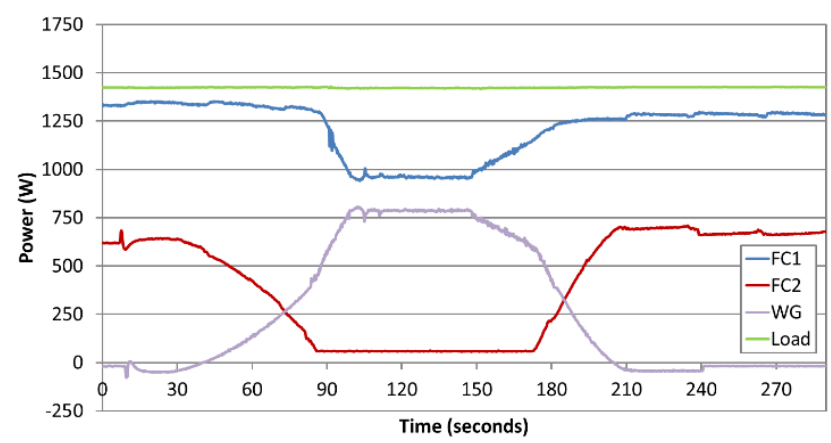

Figure 10. Power output and load demand, during test II

Regarding to the electrical efficiency of PEMFCs, the increase of wind generator power output reduces the power generated by FC1 and specially FC2 (Figure 11). Therefore, the efficiency of FC2 is reduced to the one that it has at idle state, whereas FC1 increases its efficiency from 42 to $50 \%$.

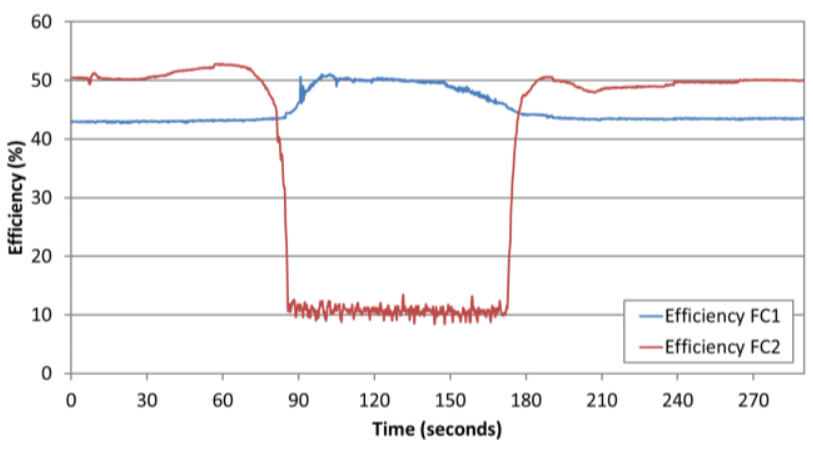

Figure 11. Efficiency of the PEMFCs, during test II

Line-neutral voltages during the test remain fairly constant between 229 and 230V, as shown in Figure 12. On the other hand, the voltage harmonic levels for the first 21 harmonics of the phase one are presented in Figure 13. The maximum, average and minimum harmonic levels have similar values, showing that there is not any event which introduces harmonic distortions in the system.

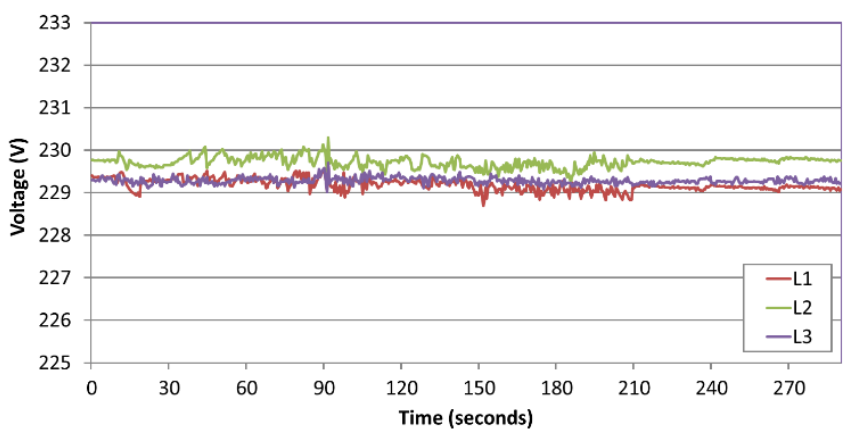

Figure 12. Line-neutral voltages, during test II

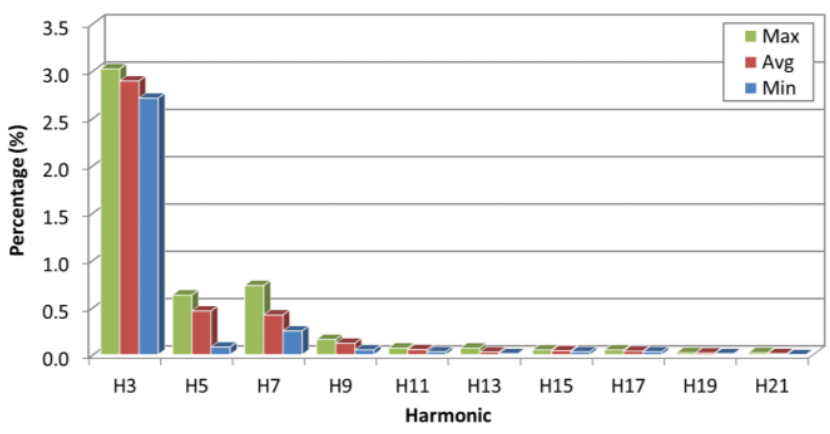

Figure 13. Voltage harmonic levels of phase one, during test II

The connection of the wind generator slightly reduces the THD value of the system, as shown in Figure 14. During this test, the THD value remains below $3.3 \%$ for all phases, complying the EN50160 standard.

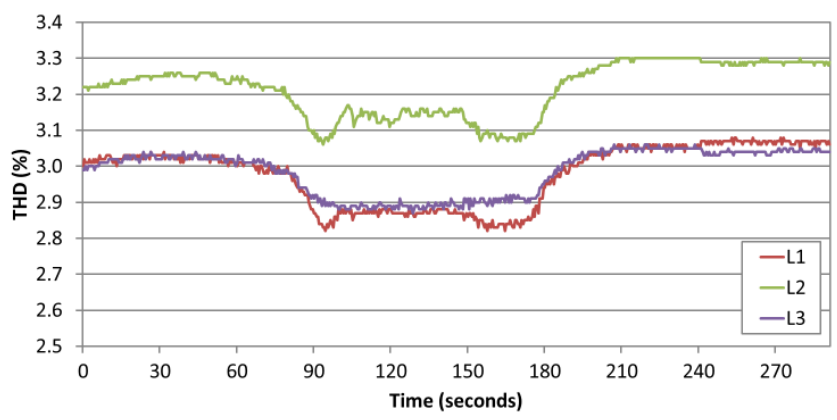

Figure 14. Voltage THD evolution during test II

\subsection{Test III. Starting of electric motors}

Electric motors start-ups in small isolated networks can be problematic as they demand an important quantity of power to energize the magnetic cores. Therefore, it is expected that significant voltage drops and THD value increases will appear during this test.

Figure 15 shows the active power variation of the different devices connected to the microgrid. As can be seen in this figure, there is an initial load demand of $0.9 \mathrm{~kW}$. Then, there is a high increase of power demand when the threephased electric motor is connected. This initial peak achieves a value of $4 \mathrm{~kW}$ approximately. After this initial peak, motor power demand is gradually increased, until a total load demand of $1.4 \mathrm{~kW}$ is reached. Then, the electric motor is disconnected from the microgrid. 


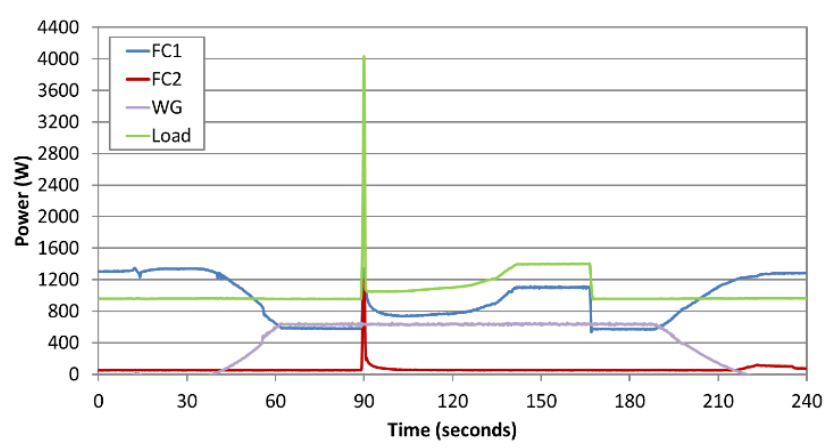

Figure 15. Active power variation during the starting of an motor, during test III

As expected, there is a voltage drop in all phases which achieves a maximum value of $12 \mathrm{~V}$, as shown in Figure 16. Therefore, the voltage drop produced by the start of the motor is within the allowed range of the EN50160 standard. However, it should be pointed out that the electric motor is quite small and it is started without any mechanical load.

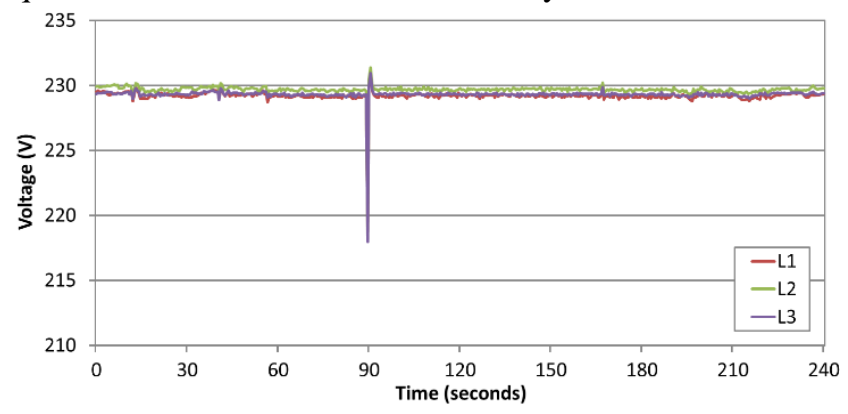

Figure 16. Line-neutral voltages, during test III

In Figure 17, the maximum, average and minimum voltage harmonic levels recorded during the test are presented. The third-harmonic voltage reaches a maximum value of more than $10 \%$ and it is registered during the motor start-up. As in the previous test $\mathrm{I}$, the duration of this event is quite short and therefore, there is no significant impact on the quality of supply.

Similarly, the voltage THD reaches a maximum value of $9 \%$ during the motor start-up. Once the motor has started, the voltage THD decreases to values lower than the previous ones, as shown in Figure 18.

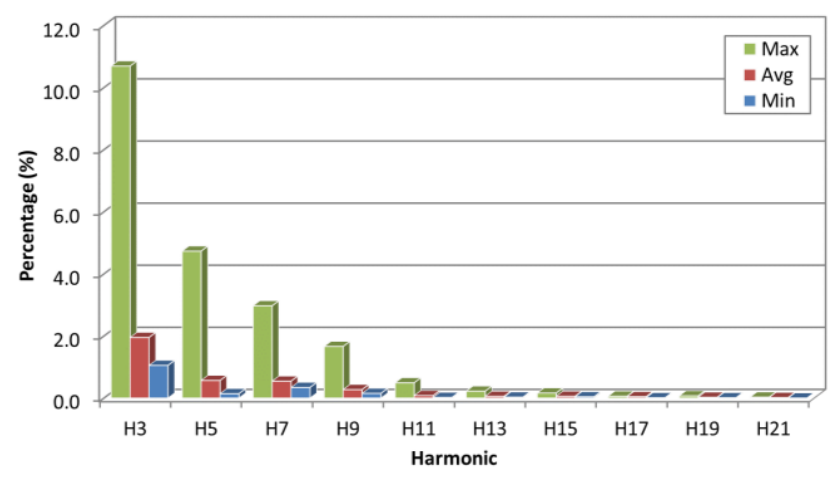

Figure 17. Voltage harmonic levels of phase one, during test III

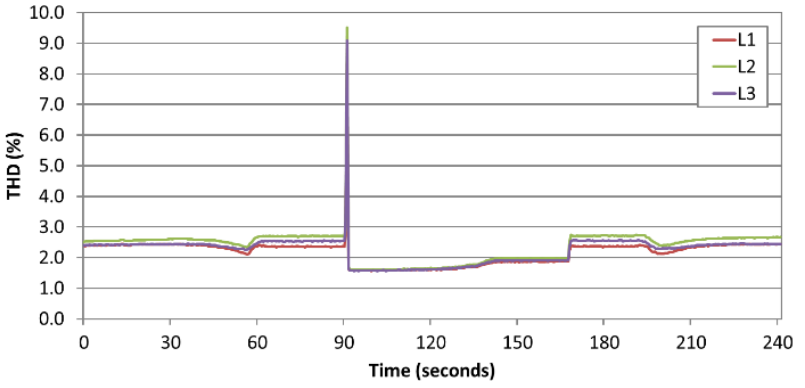

Figure 18. Voltage THD evolution, during test III

\subsection{Test IV. Hydrogen supply failure}

In this test, a failure of hydrogen supply is caused by closing the main hydrogen supply valve of the FC1. As a consequence, the disconnection of that fuel cell system is produced. The objective is testing the capability of the system to accommodate the load demand with the generated power by the other fuel cell (FC2) and the wind generator.

As can be seen in Figure 19, the FC1 power generation drops to zero 30 seconds after the beginning of the test. At that moment, the FC2 is idle and the wind generator produces $630 \mathrm{~W}$ of power. Few moments later, the FC2 starts to increase its power generation to compensate the loss of the FC1. Meantime, auxiliary batteries of the FC2 system are responsible for balancing the microgrid.

In this case, the system is able to address the loss of one fuel cell, provided that the total power demand is lower than the combined power of the wind generator and the remaining fuel cell. However, there are noticeably oscillations of the FC2 power output during more than 30 seconds, which could affect the microgrid quality of supply.

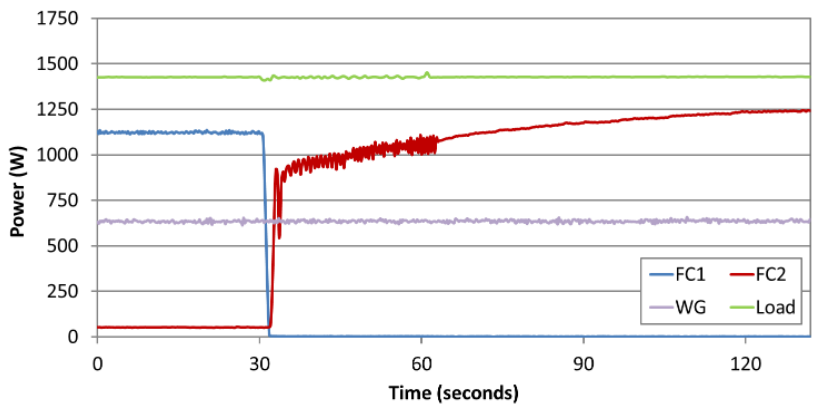

Figure 19. Active power of the different devices during a failure of hydrogen supply of the FC1

Regarding this last point, Figure 20 shows the recorded line-neutral voltages during the test IV. As expected, voltage levels are affected by the power generation oscillation of the FC2. However, these induced voltage oscillations are quite small $(<2 \mathrm{~V})$. Furthermore, the voltage THD values of the three phases remain almost constant during the test, as shown in Figure 21. Therefore, one can conclude that the quality of supply is almost not affected during the event of losing the generation of one fuel cell if the load demand is lower than the combined power of the remaining fuel cell and the wind generator. 


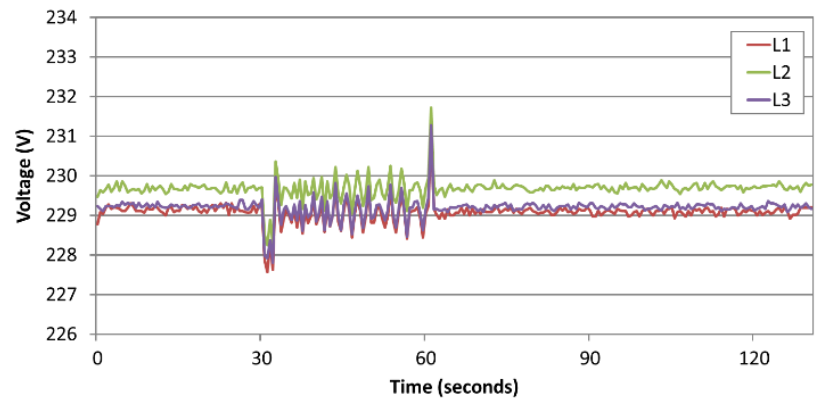

Figure 20. Line-neutral voltages, during test IV

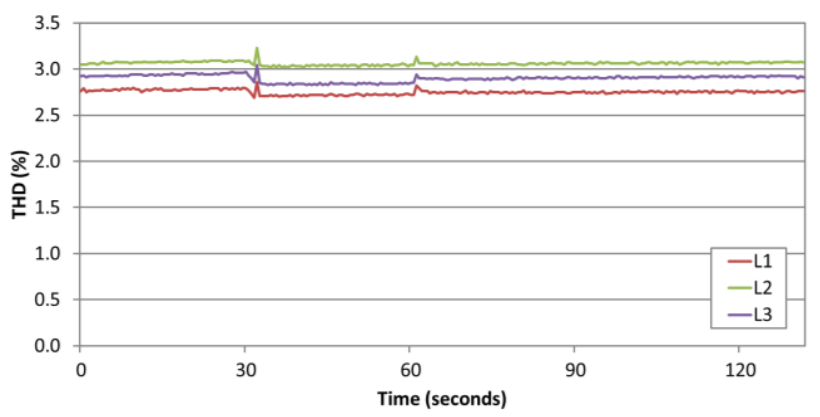

Figure 21. Voltage THD evolution, during test IV

\section{Optimization possibilities}

Several actions can be performed to improve the efficiency and reliability of the stand-alone power system. For example, a water electrolyzer could be added to the system, to generate on-site hydrogen. This is especially useful to take advantage of the surplus of energy produced by the wind generator. This way, the efficiency of the whole system will be improved. Furthermore, the hydrogen refilling needs will be reduced. Ideally, the water electrolyzer should be fully or partially dispatchable. This way, the power demand could be adjusted to meet the excess power generation of the wind turbine to improve the efficiency and controllability of the microgrid.

Another possible aspect that could be optimized is the operation of the fuel cells, which could be similar to the one carried out in [8]. This optimization is based on operating one of the fuel cells at its maximum efficiency point $(0.33 \mathrm{~kW}$ of output power), while the other one is in charge of balancing the microgrid. This improvement can be applied as long as the load demand does not excess a predetermined value $(1.2+0.33 \mathrm{~kW})$. Beyond that value, both fuel cells must be operated out of their maximum efficiency points. In order to carry out this optimization, it is necessary to set the operating points of each DC/DC converters.

On the other hand, it is always interesting to take advantage of the inherent thermal power generation of the fuel cells, to use for heating purposes. In this case, the overall efficiency (electric and thermal) of the fuel cells will be increased to values near $80 \%$.

Regarding the lifetime of fuel cells, it is advisable to monitoring the state of health of each fuel cell. This parameter must be taken into account in a real application in order to distribute adequately the workload of both fuel cells.

\section{Conclusions}

In this paper, a real stand-alone power system composed by two PEM fuel cells and a small wind generator has been analyzed. Several loads and events have been tested in order to analyze the behavior of the microgrid from the point of view of efficiency and quality of supply.

The efficiency of the microgrid is highly dependent on the generation mix but, in general, electric efficiency is high due to the use of PEM fuel cells. The overall efficiency could be improved if the thermal energy generated by fuel cells are exploited.

On the other hand, real tests have been carried out to analyze the quality of supply of the microgrid. These real tests have shown that the microgrid can cope with different real situations, such as variations of load demand and wind power generation, electric motors start-ups and loss of generation. During these tests, the recorded results have demonstrated that quality of supply is kept within the allowed range. Only during few moments, the THD and harmonic voltages have surpassed the specified values, but not for the enough time to violate the EN50160 standard. Additionally, some optimization alternatives to improve the efficiency of the presented microgrid have been proposed. Among them, the control of DC/DC converters can increase the overall efficiency without incurring additional costs.

To conclude, it should be pointed out that these real tests have been carried out for a limited period of time. In order to have a full analysis of the microgrid quality of supply, it is necessary to run the microgrid for weeks with a larger set of loads.

\section{Acknowledgements}

The work presented in this paper has been supported by the Basque Government (Ref. IT 1083-16) and the University of the Basque Country - UPV/EHU (Ref. DOCREC16/10).

\section{References}

[1] "Off-Grid solar market trends report," 2016. [Online]. Available: http://www.energynet.co.uk/webfm_send/1690. [Accessed: 03-Nov-2016].

[2] N. W. a. Lidula and a. D. Rajapakse, "Microgrids research: A review of experimental microgrids and test systems," Renew. Sustain. Energy Rev., vol. 15, no. 1, pp. 186-202, Jan. 2011.

[3] K. S. Lee, H. J. Lee, S. C. Sin, J. H. Kim, T. K. Lee, and C. Y. Won, "A stand-alone fuel cell generation system design," 2011 Int. Conf. Electr. Mach. Syst. ICEMS 2011, 2011.

[4] H.-K. Chiang, B.-R. Lin, and Y.-A. Ou, "Implementation of a stand-alone fuel cell system for domestic applications," IEEE Reg. 10 Аnnu. Int. Conf. Proceedings/TENCON, vol. D, pp. 187-190, 2004.

[5] M. Bollen, Jin Zhong, and Yufeng Lin, "Performance indices and objectives for microgrids," in IET Conference Publications, 2009, no. 607, pp. 607-607.

[6] "EN50160 - Voltage characteristics of electricity supplied by public distribution systems."

[7] "EN61000 part 2.2 - Compatibility levels for low frequency conducted distubances and signalling in public low voltage (LV) power supply systems."

[8] J. I. San Martín, I. Zamora, F. J. Asensio, and J. GarcíaVillalobos, "Control and management of a fuel cell microgrid. Energy efficiency optimization," in International Conference on Renewable Energies and Power Quality (ICREPQ'13), 2013. 